\title{
SCALE AND IMPACTS OF LIVELIHOODS DEVELOPMENT ON WOMEN EMPOWERMENT IN THE SOLID WASTE SECTOR OF JORDAN
}

\author{
Motasem Saidan ${ }^{1, \star}$, Ammar Abu Drais ${ }^{1}$, Ehab Al-Manaseer ${ }^{2}$, Murad Alshishani ${ }^{3}$ and \\ Colette Linton ${ }^{1}$
}

${ }^{1}$ Department of Chemical Engineering, University of Jordan, 11942 Amman, Jordan

${ }^{2}$ GreenPlans Environmental Consultation Ltd., 11118 Amman, Jordan

${ }^{3}$ UNDP, P.O. Box 941631, 11194 Amman, Jordan

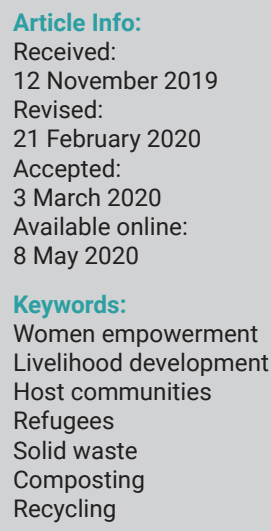

\begin{abstract}
The present study outlines a cohesive compilation of analysis of the involvement of women in decision-making and leadership in the solid waste sector in Jordan. The socio-economic challenges have been catalyzed by the influx of Syrian refugees into the host communities and camps in Jordan. Hence, deterioration of municipal solid waste services have centered on and proposed that women engagement in the Solid Waste (SW) sector to provide opportunities that aim to improve livelihoods by producing an avenue for added income generation through the recycling and sorting scheme; as well as the cost revenue implications for the municipalities. Since 2015, projects added prospects for continued engagement of women and have drastically increased their involvement by filling management positions in the development and operation of municipal SW Transfer Stations (TSs), including heading the design and operation of the TS, and the recycling project. While 54 employment opportunities were created within North Shouneh SW pilot project; 37,794 women jobs of recycling and composting were made available by the cash for work initiative throughout 2016-2017, as well as, 60 women were employed in Zaatari camp. Moreover, when $\mathrm{CBO}$ are directly involved, there has been more opportunity to engage women in employment in the solid waste sector.
\end{abstract}

\section{INTRODUCTION}

Solid waste management as an integrated system can be a gateway for innovation, leading to sustainable options for development and increased community resilience. Hence, the increased production of solid waste in communities experiencing population growth is leveraged as an opportunity to positively integrate solid waste back into the socio-ecological metabolic system. Notwithstanding that solid waste transforming into a valuable resource can promote shared goals around building resilience (i.e. job creation, recycling, reuse, reduction of waste, and the empowerment of women).

The natural resource demands of the increased population, resulting in part due to multiple refugee immigrations over the past decades in Jordan (Al-Addous et al., 2019; 2020; Al-Awad et al., 2018; Aldayyat et al., 2019; Al-Hamamre et al., 2017; Saidan et al., 2017a), have strained solid waste services and operations while increasing solid waste production, translating into seemingly unsurmounta- ble challenges, which have been negatively restricting community resiliency and impacting public and environmental health (Alrabie and Saidan, 2018; Aboelnga et al., 2018; Jabr et al., 2019; Khasawneh et al., 2019). The total population in Jordan is estimated at 9.5 million, including about 2.9 million guests (Malkawi, 2015; Saidan et al., 2018; MWI, 2015; Saidan, 2019), consisting of Syrian, Iraqi, Palestinian and other populations. However, by 2050 it is expected to double (Saidan et al., 2019).

The design and implementation of innovative solutions is urgently needed to bridge the socio-economic resiliency and safeguard the existing natural resources of host communities is underscored in the national and regional strategies in Jordan (Saidan et al., 2020). Moreover, the governing the intended targets for the solid waste sector were lain out in the Jordan National Vision and Strategy and the National Municipal Solid Waste Management Strategy, followed by their rationalization into the Regional level for the North and Central Regions. Regions of core concern are those located in the north of Jordan, as their populations 
catalyzed and their infrastructure further strained by the influx of refugees since mid-2013. The distribution of registered Syrian refugees in the major governorates, as shown in Figure 1, are namely Amman (29.4\%), Mafraq (24.3\%), Irbid (21.0\%) and Zarqa (14.5\%) (UNHCR, 2018).

In searching for an alternative to the deterioration of solid waste services and efficiency, incorporating women into the development has been and continues to be investigated. Recent ongoing projects have centered on and proposed that women lead associations for recyclables collection at the household level, which are then collected and sorted at the municipal level. This in return offers economic and employment opportunities for women in Jordan. For instance, the newly established composting facilities have carved out specific roles for women in the production of such products that are socially acceptable while also impactful.

In this way, the potential inherent in the roles of women as proximate experts in the solid waste sector can evolve as a means to boost the socio-economic opportunities of refugees hosting communities. Moreover, this emphasizes the leadership capacity of women not only in deciding how waste is discarded, but also taking a hand in establishing a foundation for meeting waste generation, environmental, climate and water-related challenges by contributing to solutions.

The participation of the female members in the municipal solid waste management is noteworthy, since they occupy the leading roles, and are able to overcome internal and external problems (GTZ, 2005). Several studies revealed the necessity to prioritize women in order to promote knowledge and attitude on effective MSW management since women are more aware of waste management specifically source separation, waste reuse and recycling (Bhawal Mukherji et al., 2016; Laor et al., 2018; Almasi et al., 2019), given their active role as the house manager is crucial (Moh, 2017). Moreover, although men are more willing-to-pay than women (Ezebilo, 2013; Bernad-Beltran et al., 2014), however, females are more willing-to-participate in waste reduction and recycling (Bench et al. 2005; Saphores et al., 2006). Iyer and Kashyap (2007) highlight the role of gender and strongly recommend the involvement of women in the promotion of recycling schemes. Notwithstanding, there has been no widely published research that has tackled the women empowerment role in the solid waste sector.

The formation of women recycler cooperatives has gained impetus in Asia and Latin America Recuperar, based in Medellin (Columbia), was created in 1983 and has 1,000

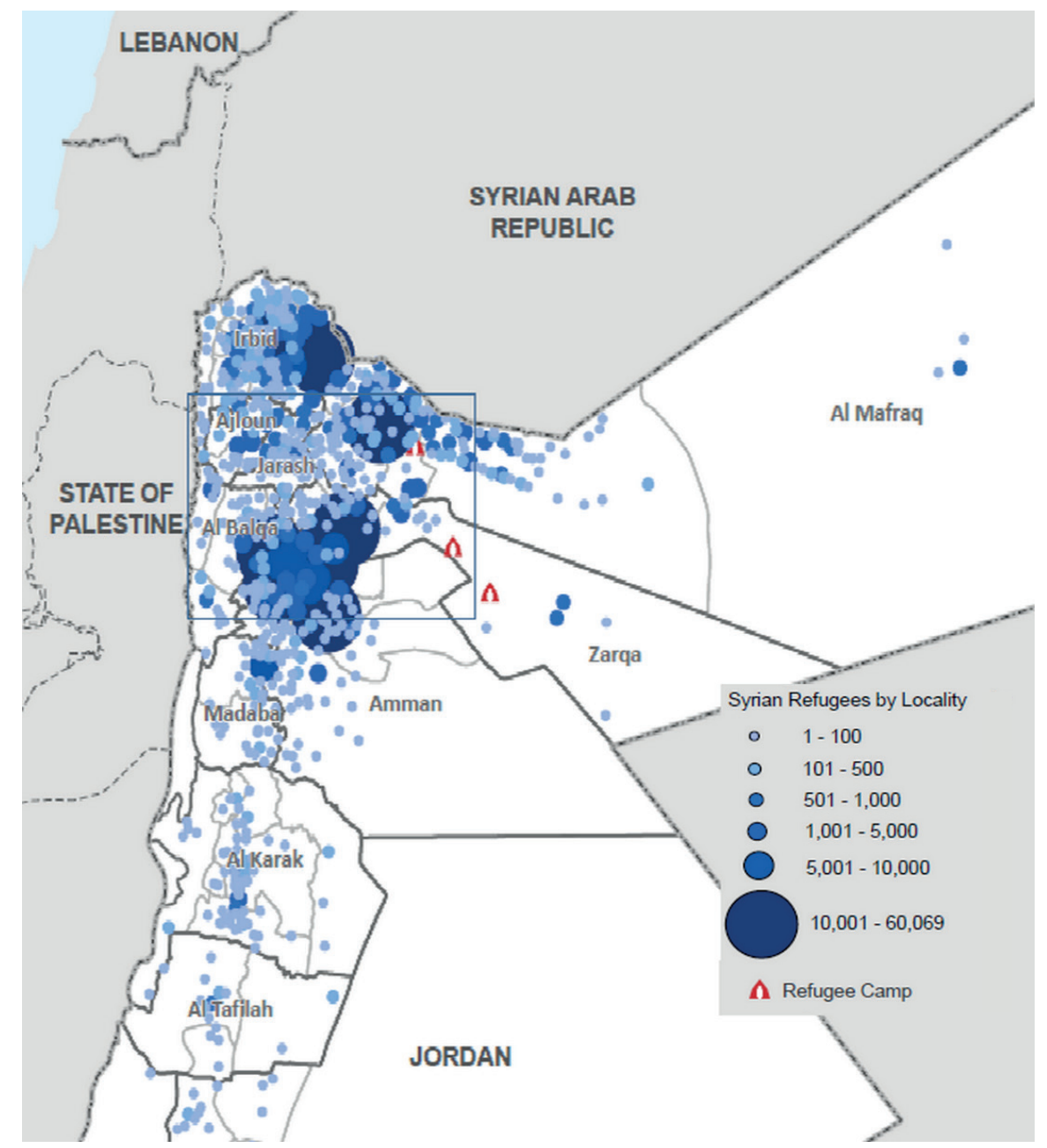

FIGURE 1: Distribution of Syrian refugees in Jordan (UNHCR, 2018). 
members, $60 \%$ of them women. In Manila (Philippines) the NGO group Women's Balikatan Movement developed as a formalized system of waste pickers and itinerant buyers of recyclables working now 17 cities and towns that comprise Metro Manila (GTZ, 2005). In Vietnam, women constitute almost $50 \%$ of employees in the MSW management industry (4500 as itinerant buyers and 500 as shopkeepers) and contribute significantly to MSW management (Mehra et al., 1996). In India more than 20,000 women work as paper pickers in the city of Ahmedabad, and up to 150,000 waste pickers in the municipal corporation of the Delhi area (Ahmed and Ali, 2004).

Before 2015, women had limited involvement in the solid waste sector at both governmental and communal levels in Jordan, despite of the active solid waste management projects in Jordan that were stimulated by the Syrian refuges influxes to the northern region of Jordan. The main objective of the present study is to provide an overview of the solid waste management projects undertaken in Jordan, as well as, the added prospects for continued engagement of women and their growing role in the solid waste sector. The focus of the present study is on the established a community-based waste sorting and recycling project in North Shouneh at Irbid Governorate, which aims at facilitating the income creation opportunities and maximizing the women involvement in the solid waste management (SWM). The "Cash for Work" initiative, which has been unleashed in refugees' camps and hosting communities, is also highlighted in the present study since women are targeted along with Syrians and youth as so-called vulnerable groups. The initiative gave an advocacy role to female Syrian Refugee workers to educate the community at the household level to sort dry wastes.

\section{METHODOLOGY}

\subsection{Case study area}

The study area includes the Tabaqet Fahel, Mo'ath Bin Jabal and Sharhabeel Bin Hasna Municipalities of the Northern Shouneh, as shown in Figure 2. Each municipality of the study area is comprised of many localities, those localities are distributed alongside with the geographic extension of the municipality.

More than half of the localities of the three municipalities have a population parentage less than $2 \%$ while almost half of them has a population percentage above $2 \%$. However, the approach of the present study included only the most populated localities with more than $2 \%$ of population percentage, which are 10 out of 23 localities. The population of these selected localities are shown in Figure 3.

In Northern Shouneh, approximately 13,145 ha of land are cultivated on annual basis, agricultural land use consisted of fodder crops ( $1,131 \mathrm{ha})$, fallow fields $(1,662 \mathrm{ha})$, greenhouses/greenhouse crops (33 ha), fruit crops (6,458 ha), fallow (3,061 ha). The amount of agricultural wastes generated from crop production varies by crop type.

\subsection{Data gathering}

A desk study was carried out for the available baseline documents (i.e. unpublished, monthly progress reports, internal memos, and minutes of meetings) and other references for collecting the technical data. Semi-structured interviews with funding agencies (i.e. UNDP, GIZ, etc.) involved in the ongoing projects targeting the host communities of Syrian refugees project, to obtain information on staffing, infrastructure, costing and working conditions. Information obtained through the interviews was crosschecked with the objective to reassess gaps and divergences of information.

\subsection{Gender statistics: women in Jordan}

Although females and males in Jordan achieve increasingly equal educational success, however, the economic participation of women remains relatively low. In terms that according to the World Bank ranking, Jordan ranked as the eight worst among MENA countries (Schwab and Sala-i-Martin, 2017), and with lowest percentages in the MENA region for the percentage of female labor force, which is at $14.4 \%$ (World Bank, 2017). Moreover, approximately $80 \%$ of women in Jordan are excluded from the labor force completely; whereas $82 \%$ of working-age men are employed or looking for work, and only $21 \%$ of women are reported with the same analogy.

At the local governmental and municipal level, women's participation in decision making roles is comparably low. Although the use of quotas has increased women's participation in government overall in Jordan, the percentage of women on municipal councils remained constantly un-

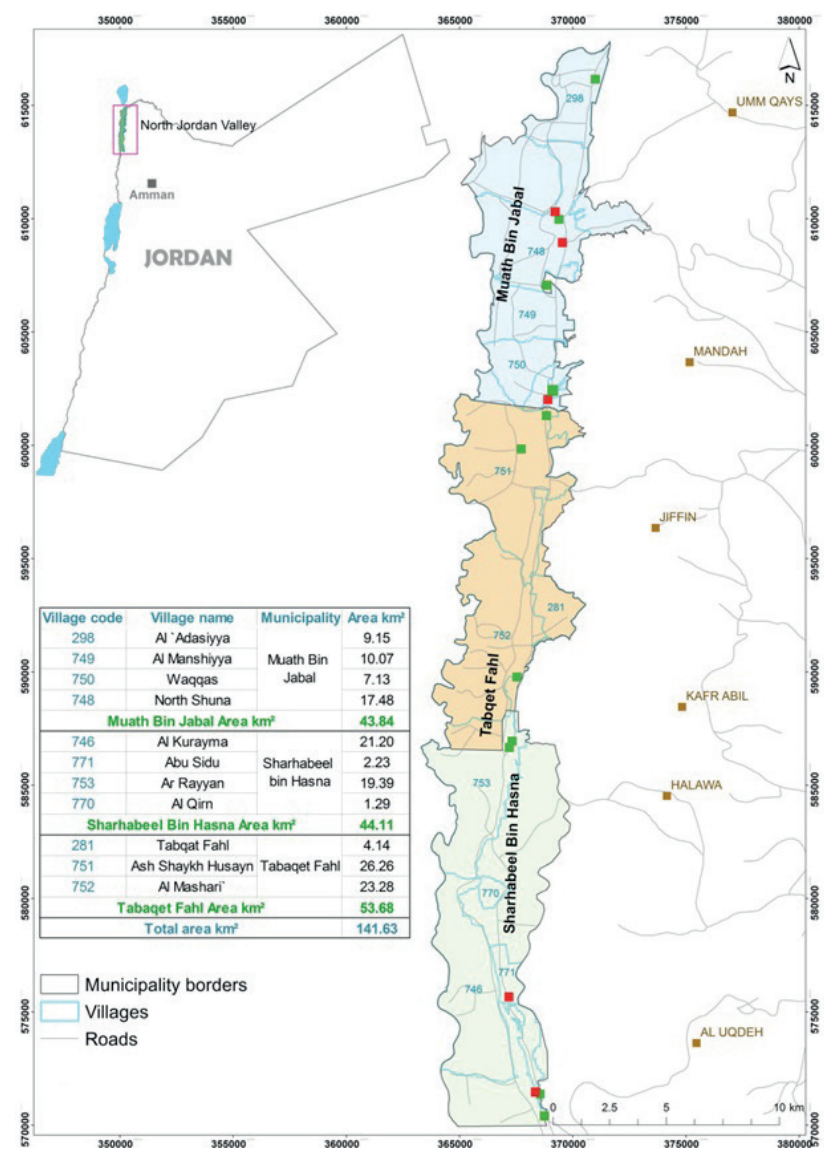

FIGURE 2: Map of selected municipalities in the study area. 


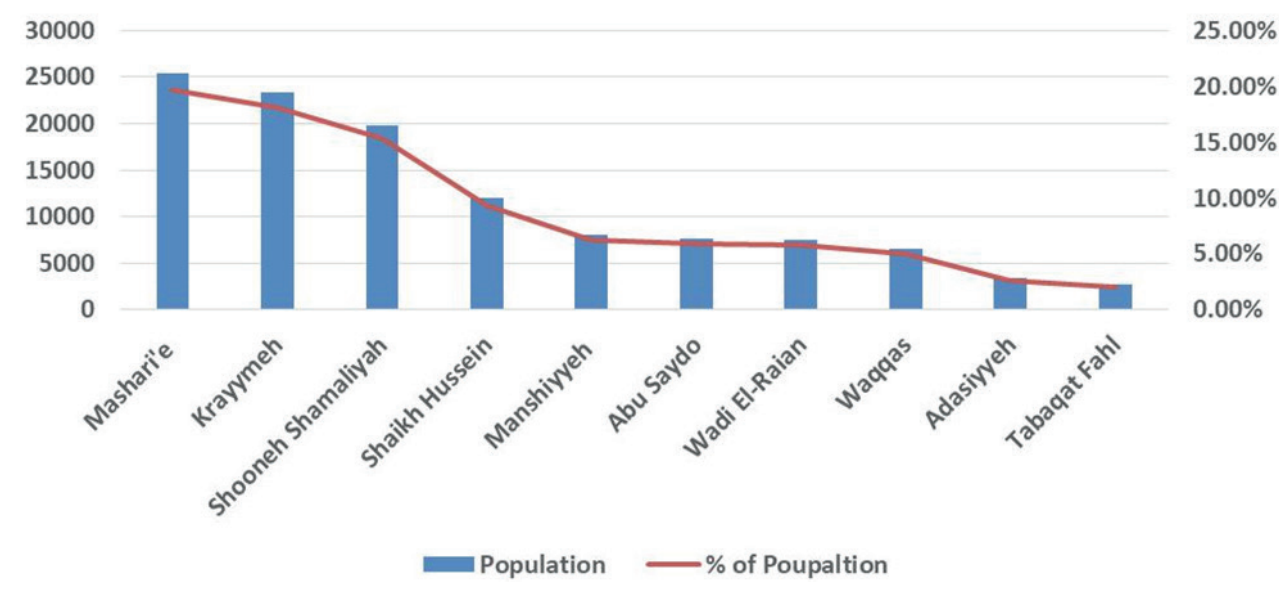

FIGURE 3: Population in all localities of the target municipalities (2017).

der 25\% between 2006 and 2016 (Al Kharouf and Al-Jribia 2016). Women's involvement in local government and municipal decision making as members of municipal councils was not only low, but decreased from $27.4 \%$ to $24.8 \%$ between 2007 and 2013 (Al Kharouf and Al-Jribia, 2016). However, Jordan set a new record in 2018 for the number of female ministers in the history of Jordan, surpassing $24 \%$ of women participation, totaling 29 women in the Cabinet (Ibanez Prieto, 2018). International indicators tracking gender equality, however, reported a decline in equality while stating a drop in economic and political participation on the part of women (UNDP, 2015). In terms of employment, the reported gender gap is wider for Jordan's most vulnerable women. For those with only a primary education, the statistic can be up to six men work for everyone working woman, given the same level of capacity (UNDP, 2015). The marital status statistics also showed that while $29 \%$ of never-married women participated in the labor market, only $15 \%$ of married women were involved (UNDP, 2015). Despite these statistics, the World Bank found that $92 \%$ of female college students are planning to work after graduation (UNDP, 2015). This is one of many studies indicating that Jordanian females desire to participate in the labor market, but due to cultural and/or economic reasons cannot achieve that. It is also noteworthy that women will likely embrace the opportunity to conduct meaningful work and contribute to their families and communities, if such an opportunity is offered in a way that is culturally sensitive.

While women may be motivated to seek employment following graduation, the cultural expectation remains that women who enter the workforce should not allow their work to disrupt their household and familial responsibilities, as these duties and expectations are delegated to women. In Jordan, for example, women are the primary caretakers of children. Women take most of the workload in family health and hygiene. Women are responsible for household waste management (Tarawneh and Saidan, 2013). Women and children drop the plastic bags with solid waste into the communal solid waste bins. Mothers educate their children in household and community hygiene and hence are the first choice to function as change agent in waste- related behaviour.

\section{RESULTS AND DISCUSSION}

\subsection{Women Involvement in SWM: Women as Proxi- mate Experts}

Women involvement in the SWM sector in Jordan is still in its beginning stages with the exception of some interventions that are almost in the final stages of implementation. The involvement of women in SWM sector is meant to offering women potential leadership roles, community engagement and auxiliary roles in SWM projects, with exclusion of roles in the physical collection, transportation and handling of wastes.

International project implementers have been looking to make headway in SWM services by incorporating women, addressing the gaps in SWM services, and assessing the socio-economics. The following projects bear such components (i.e. job provision). The incorporation of women, while a more difficult aspect due to the traditional responsibilities of women in addition to the perception overall that SWM jobs are less prestigious, these projects have struck a chord with individuals and households who are in need of an additional financial income. However, where this has been a challenge, one project in particular is trying to transform it into a leverage point, engaging women to take a leadership role as proximate experts.

Mechanisms Development for Operation of the Community Based Recyclables Receiving Stations in the framework of the UNDP-Canada led project "The Establishment of a Municipal Final Sorting Center in Northern Shouneh and the Facilitation of Local Women Engagement in Waste Recycling and Reuse Business". Developing successful mechanisms for the operation of the community-based Recyclables Receiving Stations (RRSs) was seen as a crucial challenge for the project area with the main goal of the project to encourage waste recycling practices within the targeted municipalities.

In order to develop the customized recycling mechanism within the project area (North Shouneh, Tabaqet Fahel, Mo'ath Bin Jabal and Sharhabeel Bin Hasna) a public event was initiated at an early stage of the project in order to encourage the widespread, ongoing and meaningful participation of all key stakeholders with a focus on vulnerable 
groups (i.e. elderly, women, children) in order to mobilize the public, the stakeholders of the project will be made fully aware of the intent, design, schedule impact and overall objectives of the project.

Using of the population data and relevant MSW generation rates, the MSW quantities in the study area are estimated to reach a total amount of 57,546 tons during the year of 2019 with an estimated annual quantity of 19,193 tons, 19,524 tons, and 18,829 tons for Sharhabeel Bin Hasna Municipality, Tabaqet Fahel Municipality, and Mo'ath Bin Jabal Municipality, respectively. Figure 4 presents a projection of the expected solid waste generation during the period from 2019 to 2041 in the three municipalities (MoMA, 2015).

According to the National Municipal Solid Waste Management Strategy, issued officially in 2015, the waste composition varies according to the urbanization index. Accordingly, 100 municipalities in Jordan are classified into three Classes: $A, B$, and $C$; where the urbanization index for these classes are $75-100 \%, 50-75 \%$, and $25-50 \%$, respectively (MoMA, 2015). Based on the proposed municipal solid waste composition according to Class C- Urbanization Index, $65 \%$ of the original solid waste quantities is food waste, $9 \%$ is paper and cardboard, $9 \%$ is plastic, $2 \%$ is metal, $2 \%$ glass, $3 \%$ is textile, $5 \%$ is yard waste, and $5 \%$ is other waste types (MoMA, 2015).

The activities of pilot project were undertaken in four sessions (ten working days in each session) throughout June, July, August, September, and November 2019. The working time was 5 hours per day (9:00 AM-2:00 PM). The total number of women engaged in the project during the reporting period is (54) women, who were distributed as of the following:

- 16 women worked at the Final Soring/Recycling Center, exists at the Northern Shouneh Transfer Station (JSC-Irbid);

- 12 women worked in the field for collecting waste at community level in Mo'ath Bin Jabal;

- 9 women worked in the field for collecting waste at community in Tabaqet Fahel;
- 16 women worked in the field for collecting waste at community in Sharhabeel Bin Hasna.

The final sorting/recycling center has been operated during the reporting period on a daily basis to receive and sort waste of marketing value into subcategories. Women had mainly practiced a limited waste processing activities on: cardboard baling, cardboard shredding, plastic baling, and waste sorting line operating. Plastic shredding is not applicable because the machine is crushing only the hard plastics. No activities for producing briquettes/ pellets from organic waste are reported as the machine is out of service.

The positioning of the container was optimized during the reporting period and the collection team were aware of the new locations. The modifications aimed to increase the filling up and optimize the efficiency. All of the containers are coded with specific numbers and the coordinates were identified. The collection timing and routes were updated during the reporting period in line with what recommended in waste routing collection plan.

To increase the waste recycling rates within the project area, Green points were established. Green Points - a single-stop for the reception of multiple receptacles (paper, plastic, glass and metals). The project sought out the assistance of interested community based organizations (CBOs) which would be capable of providing continuous support and technical assistance to the women managing the Green Points. In this way, the women involved in the cooperative framework for the collection of recyclables could benefit from an incentive mechanism: the more recyclables received at the Green Points, placed throughout the neighborhoods of the selected regions in northern Jordan, the greater the incentive they would receive. The mechanism provides opportunities that aim to improve livelihoods by producing an avenue for added income generation through the recycling and sorting scheme; as well as the cost revenue implications for the municipalities. Accordingly, the total number of the existing Green Points established over the projects area is shown in Table 1 according to the existing distribution.

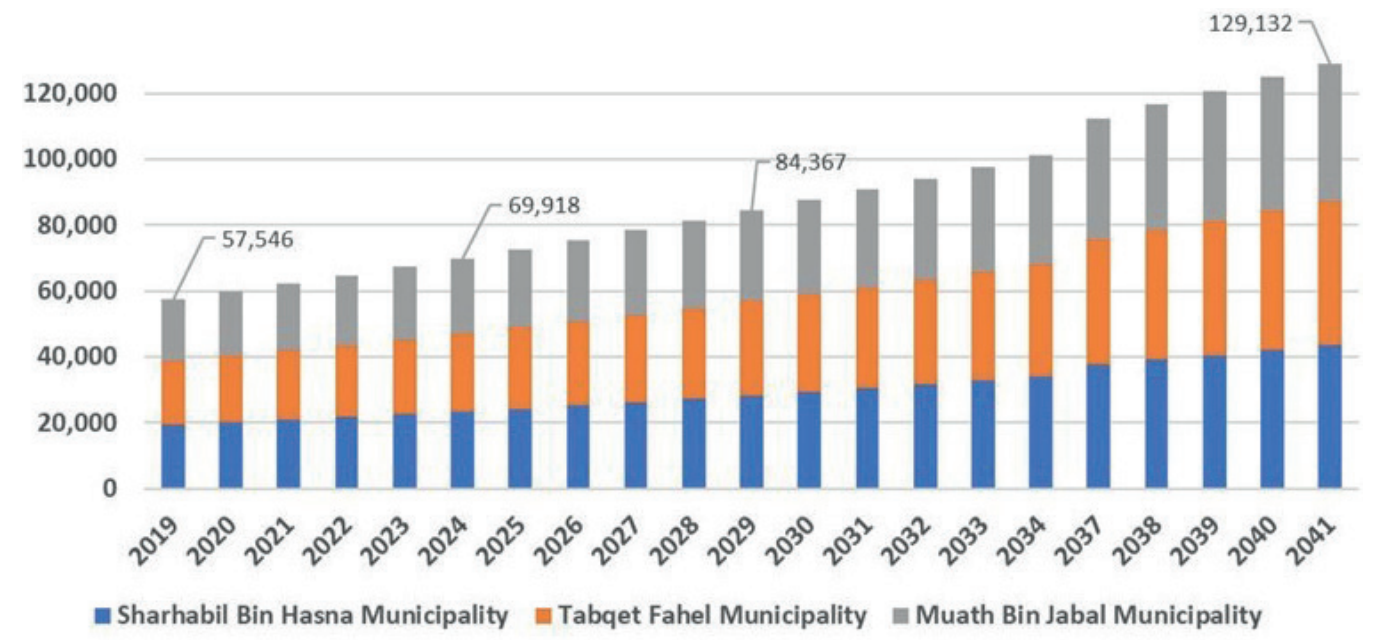

FIGURE 4: Projection of municipal solid waste generation (2019-2041) (MoMA, 2015). 
TABLE 1: Total number of the existing Green Points established over the projects area.

\begin{tabular}{l|cccc}
\hline Municipality/ Area & No. of Green Points established & Total no. of plastic bins (770 liter) & Total no. of steel cages (2000 liter) \\
\hline Mo'ath Bin Jabal & 12 & 31 & 4 \\
\hline Tabaqet Fahel & 11 & 29 & 14 \\
\hline Sharhabeel Bin Hasna & 6 & 74 & 1 \\
\hline Total & 29 & & 1 \\
\hline
\end{tabular}

The women had collected around 63.3 tons since the start of June 2019 from the entire study area. Figure 5 shows the total waste amounts collected in the pilot project by women in June, July, August, September, and November 2019.

The proposed MRF lies within the Northern Shouneh district in Irbid Governorate at an existing old dumpsite (to be closed upon rehabilitation of the transfer station). The transfer station there is already serving many Municipalities, as a transfer station to other landfills where the number of served municipalities will decrease by the establishment of another transfer station at Al-Taybeh. The transfer station will continue working as a solid waste transfer facility. Added to that a sorting center (final sorting of solid waste) will be constructed. The project includes rehabilitation and upgrade existing facilities and construction of a new sorting center. This will decrease the delivery of waste to the landfill, and this will increase the lifetime of the destination landfill. It will be used to provide Livelihood opportunities, capacity building and proper training for more than 60 women and men from the local community to run such facility through collection, sorting and marketing. This station will serve as a final sorting facility of solid waste collected at the Green points from Mo'ath Bin Jabal, Tabaqet Fahel and Sharhabeel Bin Hasna. The site lies on a total area of 80 dunums, of which, 10 dunums will include the transfer station as well as the new intended Sorting Center. It must be noted that the location was used as solid waste landfill for about 30 years. Officially is supposed to be closed, but, still used in many cases of breakage of vehicles.

Furthermore, through the aforementioned project, the feasibility and viability of establishing a briquettes production plant from organic, agricultural materials, as well as, paper and cardboards by women associations is to be evaluated, given its potential benefits to the community. It is estimated that approximately 3,500 tons of agricultural waste are generated annually. However, the proposed briquettes production unit shall have a design capacity of about 100 tons per year and will utilize the locally available agricultural waste, scrap wooden furniture and non-recyclable paper and cardboard as input materials for the plant.

Based on comprehensive assessment on the project scope of the recyclables quantities for each target municipality. The projected recyclables quantities assessment results are shown in Figure 6 for Sharhabeel Bin Hasna, Tabaqet Fahel and Mo'ath Bin Jabal municipality respectively.

As shown in Figure 6, Tabaqet Fahel municipality has the highest quantities of paper and cardboard and plastic with 1,757 tons and 2,576 tons in 2019 and 2029, respectively. Metal quantities is almost the same among all municipalities, where 384 tons, 390 tons and 377 tons is expected to be generated from Sharhabeel Bin Hasna, Tabaqet Fahel and Mo'ath Bin Jabal municipality, respectively in 2019, while the quantities are estimated as 565 tons, 573 tons and 550 tons in 2029 for the same municipalities, respectively. Glass quantities also represents the

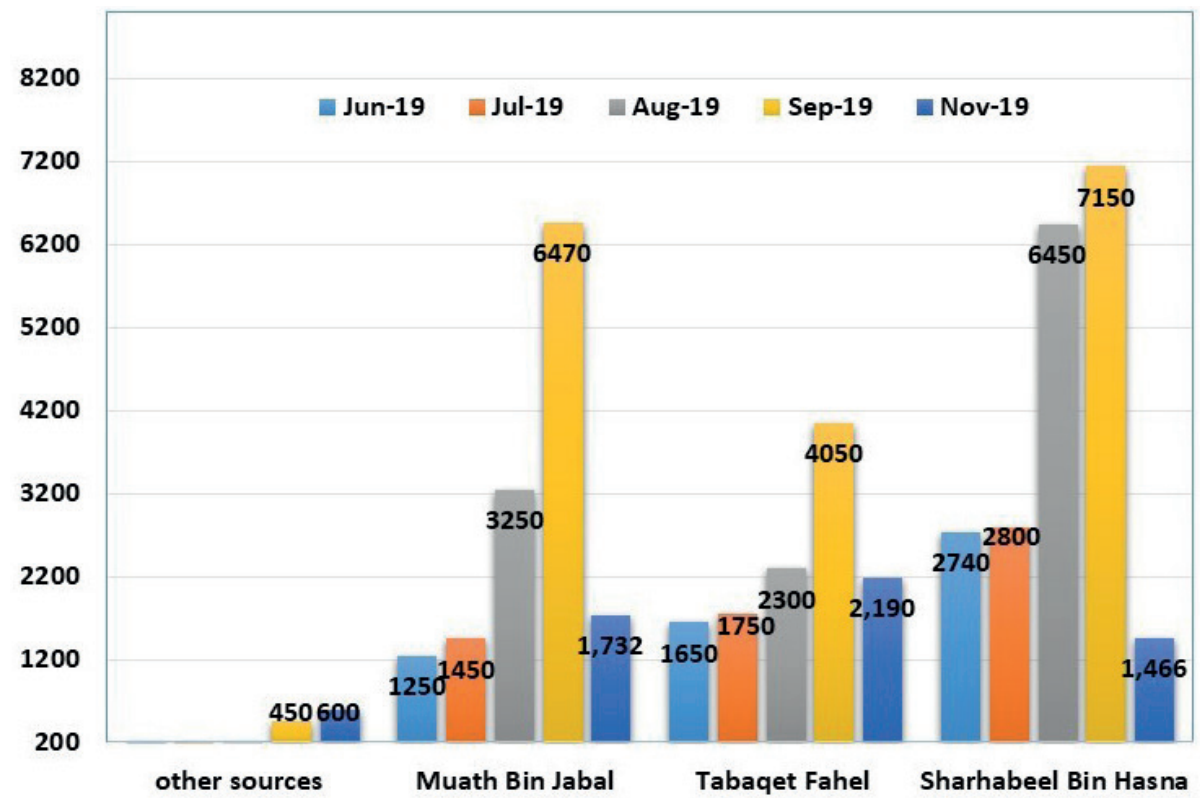

FIGURE 5: Total waste amounts (kg) collected by women in in June, July, August and September 2019. 


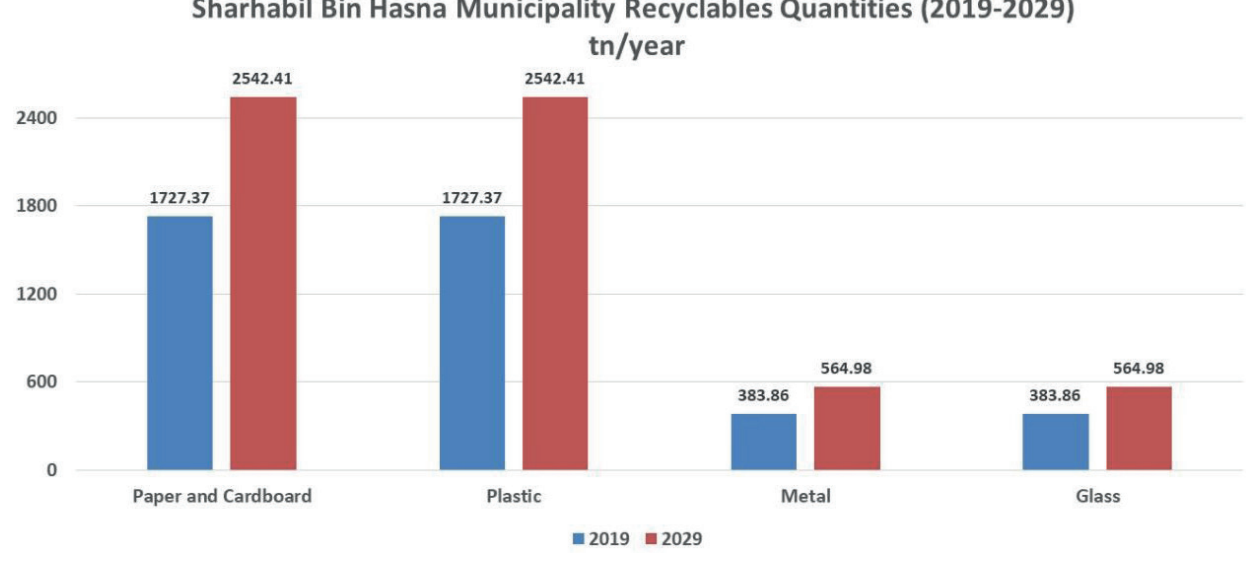

Tabqet Fahel Municipality Recyclables Quantities (2019-2029)

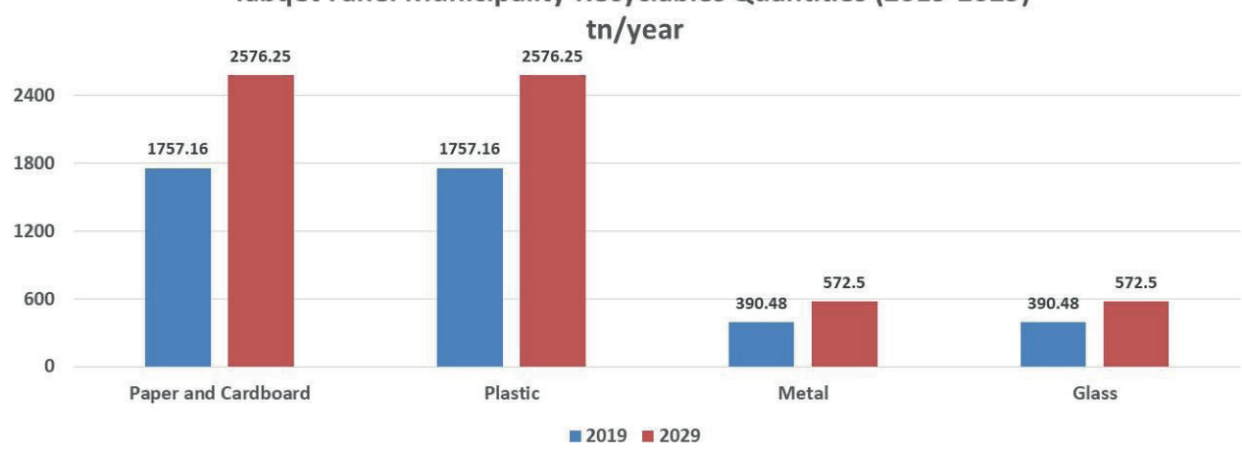

Sharhabil Bin Hasna Municipality Recyclables Quantities (2019-2029)

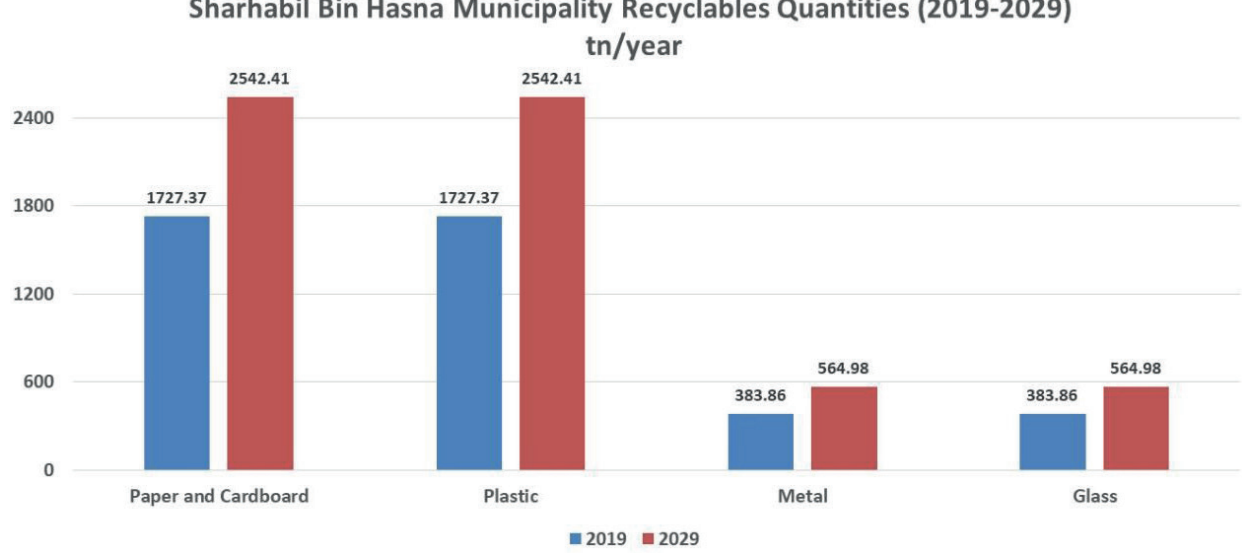

FIGURE 6: Potential quantities of collected recyclables in the three municipalities.

same amounts for the three municipalities with 384 tons, 391 tons and 377 tons are expected to be generated from Sharhabeel Bin Hasna, Tabaqet Fahel and Mo'ath Bin Jabal municipality in 2019, respectively, compared with 565 tons, 573 tons and 550 tons in 2029, respectively.

\subsection{Establishment of umbrella cooperative}

The participation of community based organizations (CBOs) in the recyclables collection scheme translated into livelihood opportunities for women in this mechanism. According to UNDP parallel project "Livelihoods Intervention" which aims to engage woman in the field of waste management and to generate employment opportunities within North Shouneh, a total of 20 full time positions (13
Green Points Operators, 7 Support Staff) and 13 part time positions (women for waste collection) are to be opened up to women in the communities to operate the community based Green Points (16 CBOs hosting Green Points in total), participating and innovating the collection of recyclables and ensuring their delivery into the designated bins located within their community. Figure 7 shows photography of different activities for the women engaged in the project. The location of the CBOs facilitate accessibility for the women workers, who are tasked with collecting recyclables from residential areas and turning them over to the Green Points.

The means for propelling the women participation and incentivizing collection of recyclables also take another 

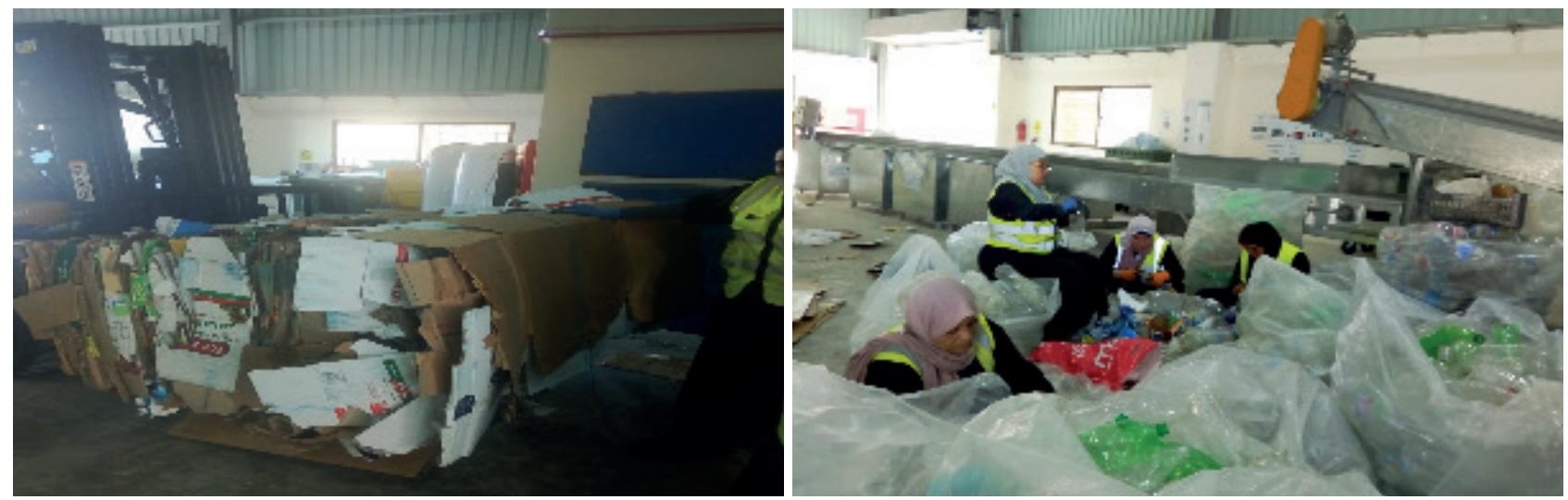

(a) Processing activities at the final sorting center
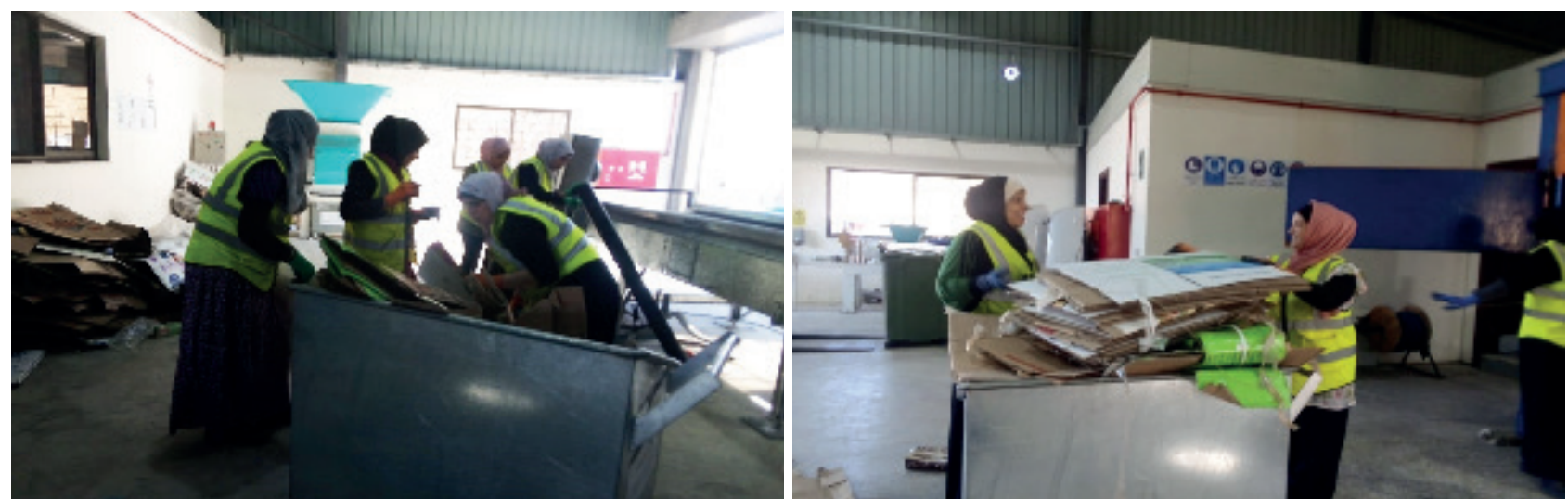

(b) Processing activities at the final sorting center
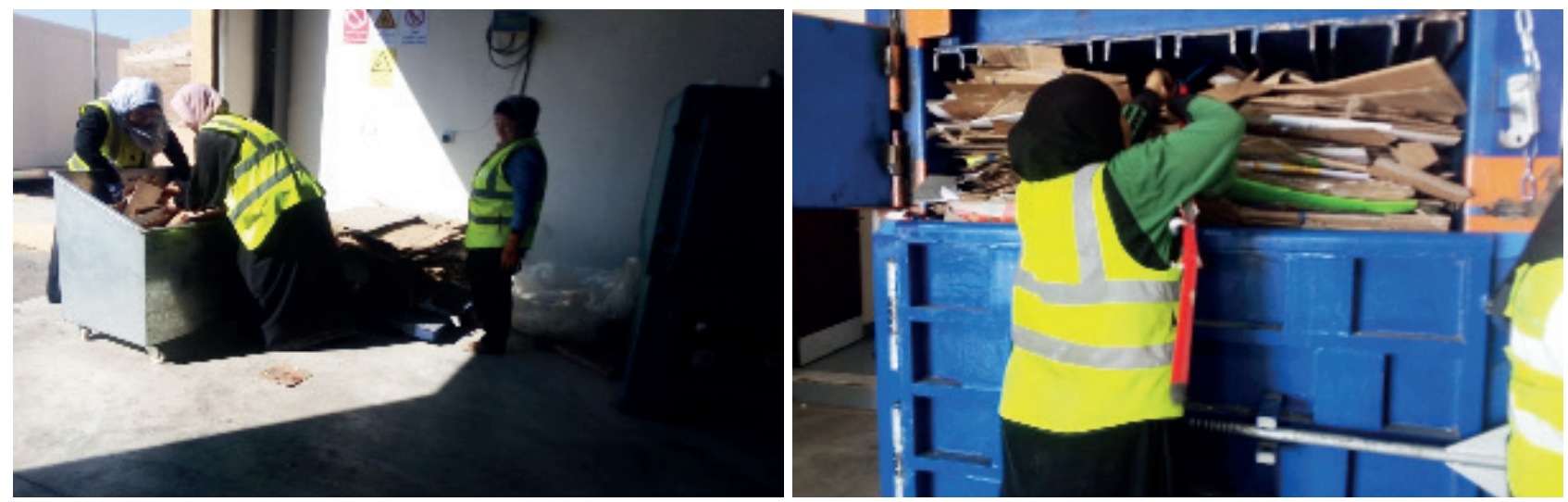

(c) Further waste sorting activities at the center

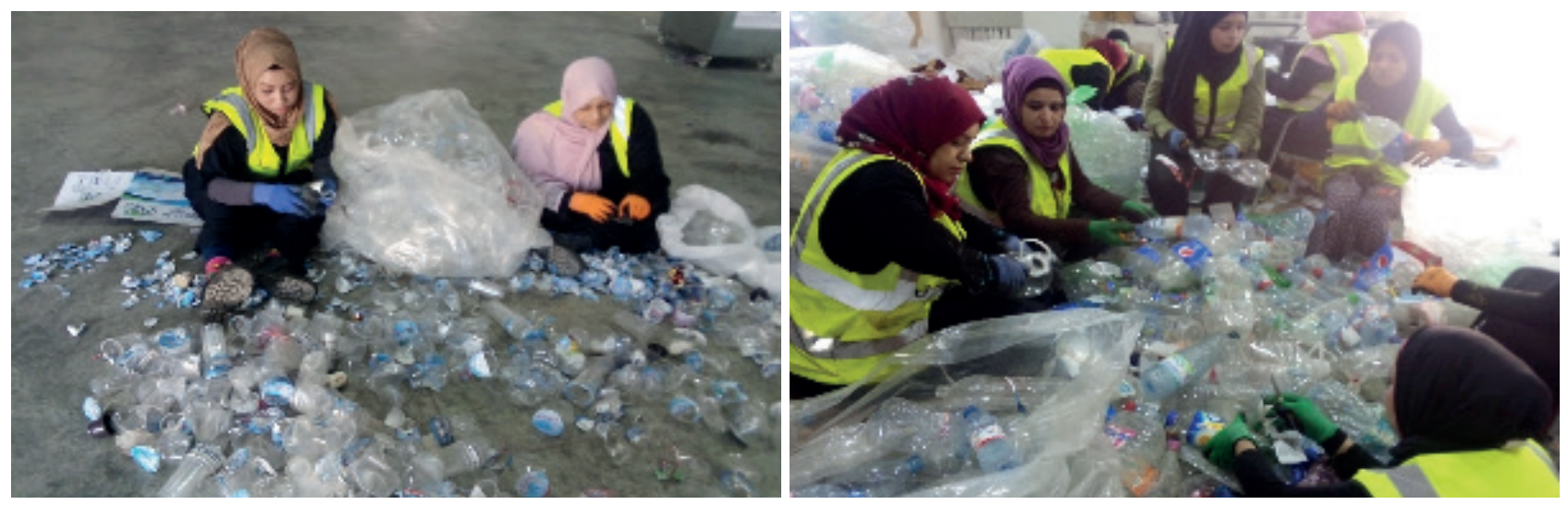

(d) Sorting of plastic according to the sub-categories 


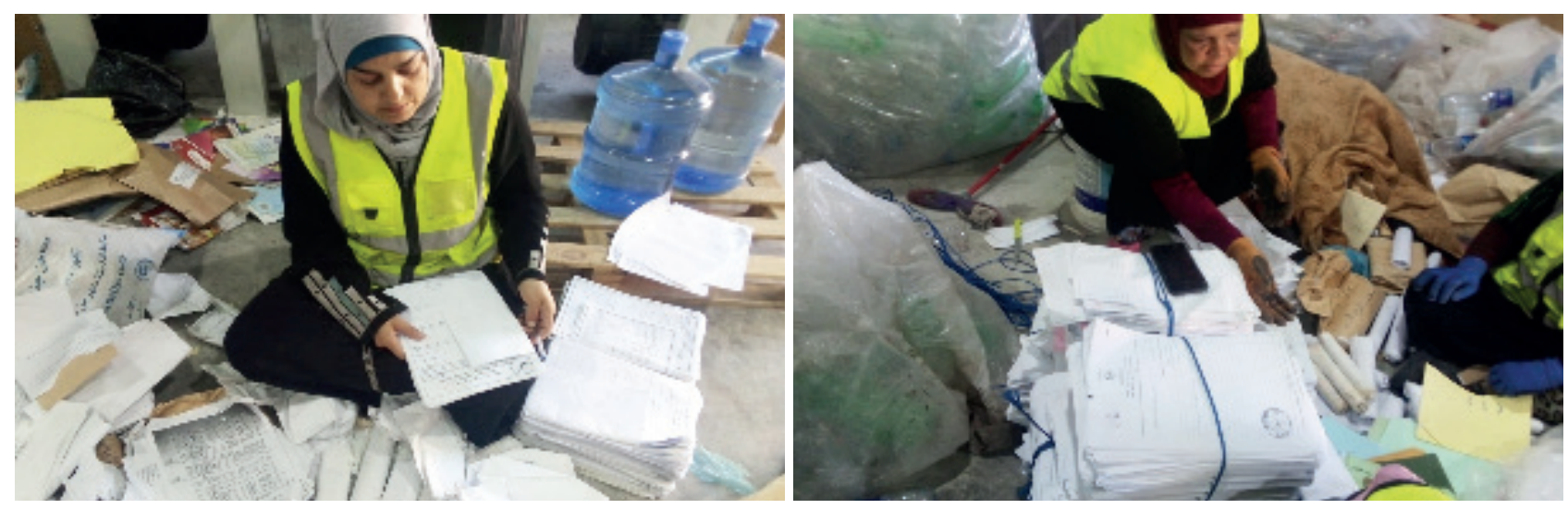

(e) Paper sorting and baling

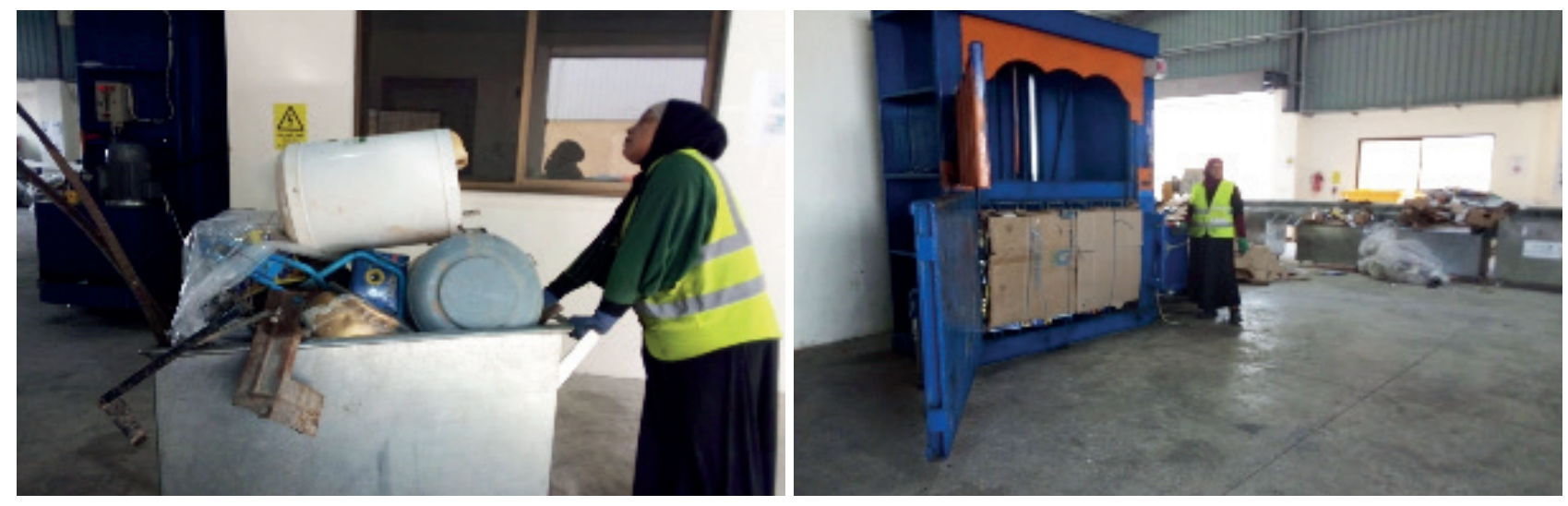

(f) Scarp waste processing
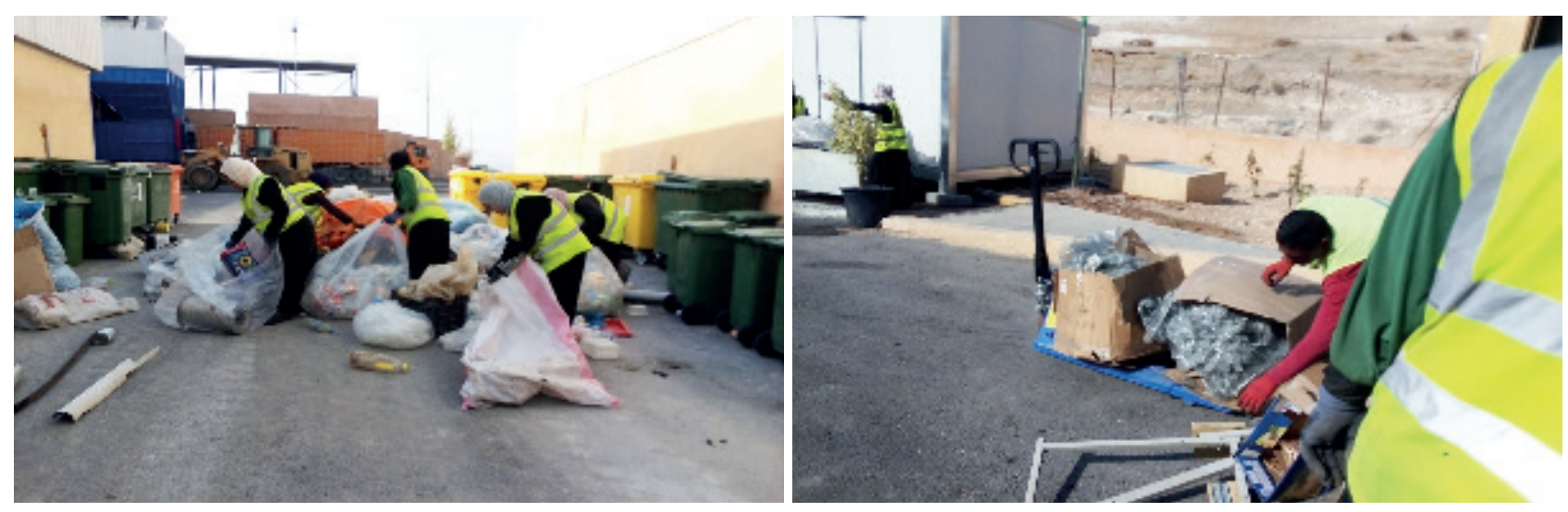

(g) Further plastic sorting at the final recycling center
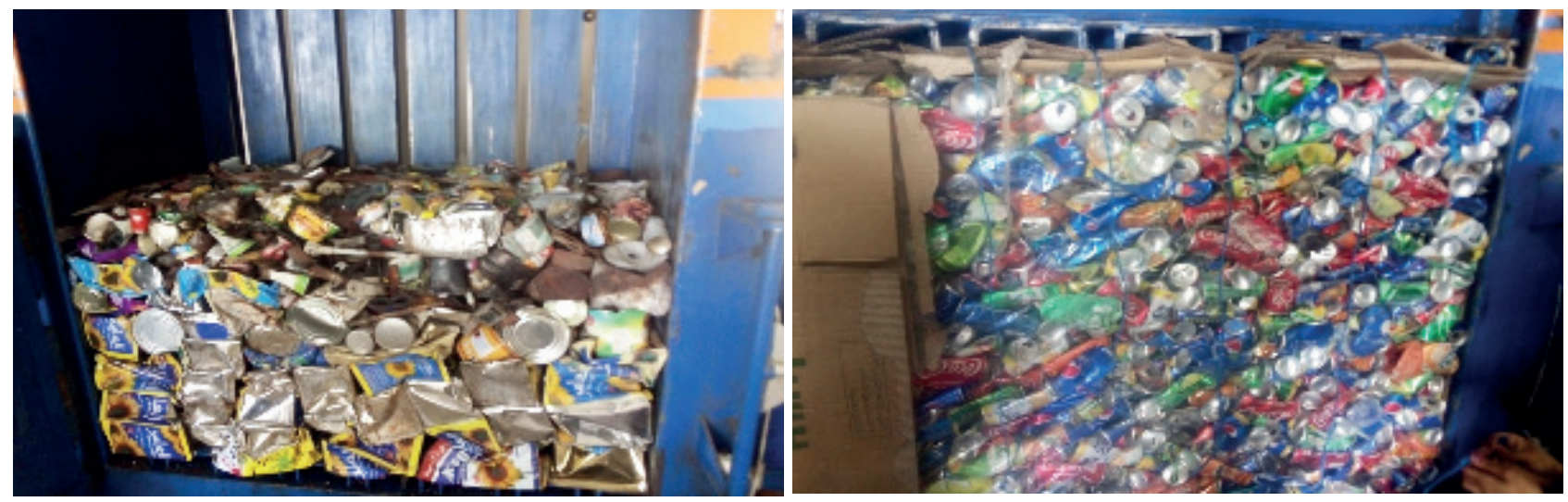

(h) Baling of steel/iron waste and aluminum 

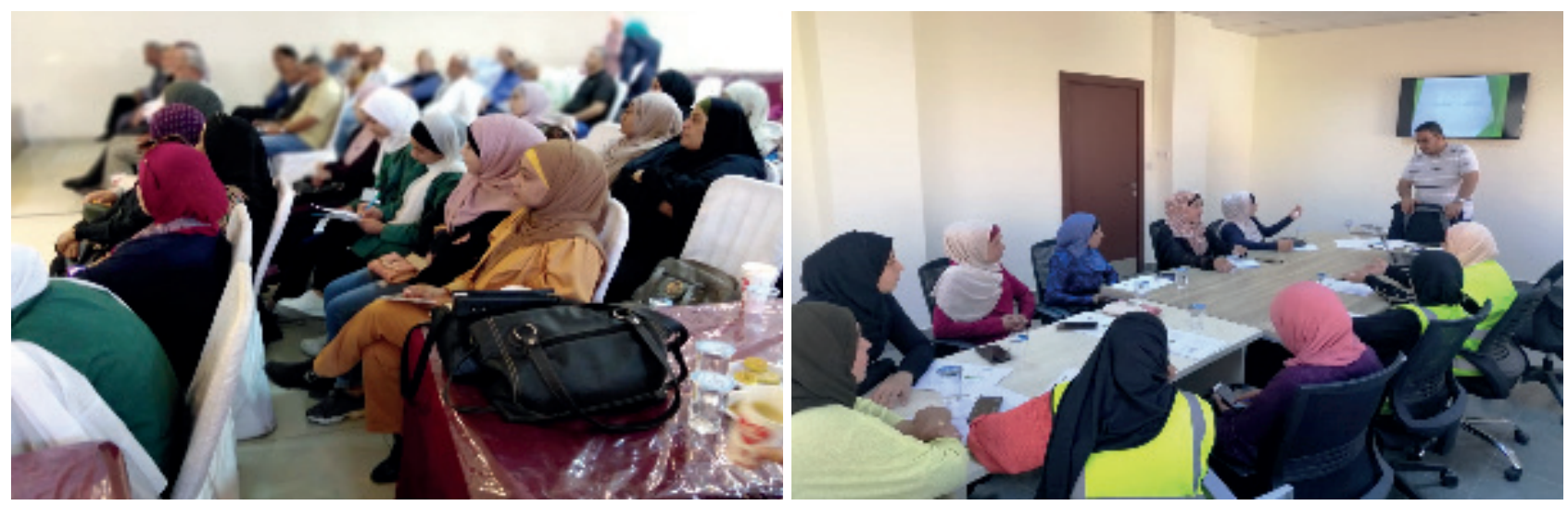

(i) On-job training activities for the women engaged in the project

FIGURE 7 a-i: Pictures of different activities for the women engaged in the project.

form: the establishment of an Umbrella Cooperative to coordinate efforts and manage the shares of accrued revenues from recycling operations, distributing monthly salaries through cooperative revenues and others as shares, as well as, designating funds in ways to additionally incentivize collection, pride in recyclables and SWM sector work and uplifting the communities. The Umbrella Cooperative also is a mean for the workers based at the CBOs, as well as, at the sorting station to gain shares in both the collection of recyclables and sorting station operations. This is of particular importance for the women who start their works at the sorting station. To ensure the sustainable operations of the sorting facility, during the first 4 years (2019 to 2022) the facility will employ 10 individuals (supervisors, operators, mechanics, etc., in addition to the women sorting workers). The number of employees will increase to 18 for the following 4 years (2023 to 2026), and to 22 for the following 3 years (2027 to 2029), reflecting increases in amounts of waste processed.

\subsection{Female factor: Innovation and value-added con- tribution}

The socio-economic context of Jordan is largely attributed as the driving fuel for women motivations to take part in employment opportunities that previously would not have been readily available to them. Particularly in the northern part of Jordan, women views on employment in the solid waste management activities can be summarized as of the following:

- Women in the northern Jordan would be willing to work in waste separation and recycling; guaranteed that suitable working conditions would be made available.

- Given women's primary household responsibility and chores, women and men may have different roles that are determined by the community, giving men the space of freedom in the public sphere, and leaving the private sphere to women.

- Women economic situation is a critical factor that affects society acceptance and support of economic participation the women in the solid waste activities by surpassing the set social norms. Despite the diversity of opinions regarding what is culturally acceptable in terms of women in the workforce, the poor economic situation and the guarantee of a decent living drive women to work in any sector.

- Women economic activity can generally generate higher incomes for their families, as well as the possibility of becoming empowered decision makers.

- Women should be pioneers and manage the implementation of the project, but the participation of women in community decision-making on waste disposal is largely a missing element, requiring explicit facilitation by the employer and/or project.

- Raising awareness and training on the right mechanism of solid waste management are essential in achieving the desired project objectives. This cannot be effectively achieved without women taking part due to the fact that women are responsible for managing the household waste, and are the primary actors in reusing solid waste (proximate experts).

- There are many challenges facing women working in the solid waste sector which include socio-cultural factors related to gender roles, norms and stereotypes, in addition to the subjective and economic factors which are relevant to rewards of this activity.

While these characteristics can be obstacles to increasing women inclusion in the workforce, there are some opportunities to promote skilled labor that draws a connection to traditional roles and translating them into meaningful, skilled work in the solid waste sector. Specifically, as women are positioned at the helm of deciding what items are purchased; and how, what, and when they are discarded.

Globally, 70-80\% of all consumer purchases are driven by women, through a combination of their purchasing power and influence. When it comes to typical household items that will eventually make their way to the curb for recycling, the purchasing power is even higher. In addition, since women generally make up the majority of municipal service users, hence, this makes them the ideal beneficiaries of solid waste management projects, because they usually provide improvement for services, a higher priority than men (Asi et al., 2013). 
Previous and ongoing projects in Jordan have offered the women the role to lead associations for recyclables collection at the household level, which are subsequently collected and sorted at the municipal level. In return this offers economic and employment opportunities for women in Jordan. Moreover, as a central component to current and future projects in the solid waste management, women are determined to be proximate experts since they are capable of contributing to this sector improvement from the bottom-up.

\subsection{Other cross cutting SWM projects and women empowerment}

UNDP's “Community Based Composting to Convert Manure Waste to Resource and Create Livelihood Opportunities", implemented by Future Pioneers in Empowering Communities (FPEC), which aims to create job opportunities through compost production paired with a formidable business model. To date, the project has established a packaging facility at Al Khaldyeh women society. The compost packaging operations employ 16 women on a parttime basis.

Started in 2017, a GIZ funded project titled "Waste to positive Energy" and conducted by international NGO Action Against Hunger (ACF) in Jordan, has helped around 1,194 vulnerable individuals (550 women) around Irbid on a 50-day-fixed-term contract, where they collected and sorted waste through cleaning campaigns in the local area, later turning them into salable items to increase theirs and their families' livelihood.

For example, under GIZ's "Cash for Work" initiative, encompassed within the project entitled "Supervising the Commissioning of Composting and Sorting Plants, Their Operation, and the Marketing of Recycled Products and Compost by Municipalities" women are targeted along with Syrians and youth as so-called vulnerable groups. One of the objectives of the project is to develop a participatory system to establish labor intensive materials recovery and processing systems (sorting and recycling stations as well as composting sites) to create income generation for these vulnerable groups. It was envisioned that community groups be trained to conduct public awareness activities and increase the acceptance and public respectability of SWM activities. The project is underway in the municipalities of Greater Irbid, West Irbid, Al-Wassatya, Al-Taybeh, Greater Mafraq, Deir-Alla, Greater Madaba and Al-Karak.

Through GIZ's Cash for Work initiative, the following jobs figures were achieved (Roy and Schmid, 2018):

- 16,723 vulnerable Jordanians and Syrian refugees (22.6\% women) were employed - Direct partnership with 9 municipalities construction of recycling and composting facilities throughout 2016-2017,

- 790 vulnerable Jordanians and Syrian refugees were employed outside the camps, and 4059 refugees took part in inside the camps.

Oxfam project also utilized the Cash for Work incentive program. In this case, the setting was the Zaatari Camp in the Mafraq Governorate where Cash for Work workers collected wastes while encouraging households to separate their dry wastes. Thus, by covering about $18 \%$ of the working age population in Zaatari, this becomes as an integral part of people survival and livelihoods strategy (OXFAM, 2017). The initiative gave an advocacy role to female Syrian Refugee workers. Approximately, 200 workers (30\% women and $70 \%$ men) educate the community on recycling, collect recyclable materials from households, and process the waste into materials that can be sold to traders (UNHCR, 2017). Saidan et al. (2017) investigated the potential solid waste recycling in the camp, and proposed a feasible recycling model based on the recyclables market prices in Jordan (Saidan at al., 2017b). However, 4,237 tons of recyclables can be collected per year (over three folds of what is collected currently) with massive expansion of the existing recycling program the project will come closer to covering its running costs (OXFMA, 2017).

The projects mentioned above largely incorporate women into administrative roles and have attempted to avoid the labor- or operations-related work. In contrast, when NGOs and CBOs are directly involved, there has been more opportunity to engage women in employment on another level, as NGOs/CBOs can offer sustained services, such as providing a babysitter or coordinated carpooling, that are tailored to women who have dual roles: household and workplace responsibilities. Additionally, in either case, creating a workplace wherein segregated work spaces can be provided (in certain regions this aspect becomes more important) depending on the type of work required (physical - segregated; administrative - integration is acceptable).

\subsection{Incentive mechanism}

The direct incentives will include "cash for trash" scheme; the scheme will be designed based on points credit system whereby participating residents are encouraged to deposit their recyclable waste at the nearest Green Point in exchange for credit.

The waste deposited by the participating residents will be weighed by the employees of the supervising CBO, who will be trained on the required technology that will transfer the assigned credit to each participant based on graweight, type of recyclable, prevailing market price, as well as, on how to process credit transactions. As part of a digitized and periodically audited system that connects the local Green Points, Umbrella Cooperative, Military/Civil Consumers Cooperative, and Sorting Facility, each bale of waste generated from participating residents will need to be tagged with the appropriate serial number. This is to identify the exact amount of waste deposited by residents and weighed by $\mathrm{CBO}$.

Initial calculations illustrate that the amount allocated to reimburse participating residents might not be relatively competitive enough to incentivize broad communal participation and the depositing of average household waste volumes. It is therefore crucial to highlight that the success of this aspect of the project will depend in great part on the active participation of a minority of residents who will be able to deposit voluminous amounts of waste, as well as, 
the participation of the $\mathrm{CBO}$ ' part-time collection workers, who will be reimbursed according to the amount and type of waste they collect.

This incentive mechanism has yet to connect the benefits and revenues of the recycling operations to the larger community. As the establishment of Green Points and their operations are conducted by a select number of women and local CBOs, this represents an opportunity for the $\mathrm{CBO}$ s to promote the recycling activities. CBOs could use their new involvement with the community to survey their (the community) ideas for small-scale projects to improve public spaces, host public events, and/or other activities upon discretion of the community. The local CBOs would then pitch the projects to the Umbrella Cooperative that would have a cache of funds from project revenues to facilitate small-scale community improvement/cohesion projects.

\section{CONCLUSIONS}

As exemplified in this study, projects implemented by international organizations are institutionalizing a trickle-down effect, making women roles as core aspects of their projects in the solid waste management. Even though these positions are small in their number or in the scope of the women responsibilities, as cultural norms have a preference for segregated workstations as well as labor that avoids direct contact with collection points on the street (i.e. dumpsters, etc.), the economic pressure that confronts these women and their families has led to them looking for employment opportunities. In turn, this has given project implementers the opportunity to expand projects that bridge the needs of the solid waste sector with the needs of local, vulnerable households in Jordan. Women taking the lead as proximate experts has yet to fully take shape on the ground, yet project implementers are strategizing for the successful integration of women in such roles of responsibility, in which they coordinate and mobilize communities around the interests of improving solid waste management at the local level.

\section{ACKNOWLEDGMENT}

The authors in general, and GreenPlans for Environment Co. authors, are grateful for the support and facilitation received from United Nation Development Program (UNDP), GIZ, and OXFAM.

\section{REFERENCES}

Aboelnga, H., Saidan, M., Al-Weshah, R., Sturm, M., Ribbe, L., Frechen, F.B., 2018. Component analysis for optimal leakage management in Madaba, Jordan. J. Water Supply Res. T. 67(4): 384-396

Ahmed, S., Ali, M., 2004. Partnerships for solid waste management in developing countries: linking theories to realities. Habitat Int. 28: 467-479

Al-Addous, M., Saidan, M.N., Bdour, M., et al., 2019. Evaluation of Biogas Production from the Co-Digestion of Municipal Food Waste and Wastewater Sludge at Refugee Camps Using an Automated Methane Potential Test System. Energies 12(1): 1-11

Al-Addous, M., Saidan, M.N., Bdour, M, et al., 2020. Key aspects and feasibility assessment of a proposed wind farm in Jordan. International Journal of Low-Carbon Technologies, doi:10.1093/ijlct/ ctz062
Al-Awad, T.K., Saidan, M.N., Gareau, B.J., 2018. Halon management and ozone-depleting substances control in Jordan. International Environmental Agreements: Politics, Law and Economics 18(3): 391-408

Aldayyat, E., Saidan, M.N., Abu Saleh, M.A., Hamdan, S., Linton, C., 2019. Solid Waste Management in Jordan: Impacts and Analysis. J Chem Technol Metall 54(2): 454-462

Al-Hamamre, Z., Saidan, M., Hararah, M., et al., 2017. Wastes and biomass materials as sustainable-renewable energy resources for Jordan. Renewable Sustainable Energy Reviews 67: 295-314

Al Kharouf, Al-Jribia, 2016. The Evolution of Women's Political Participation in Various Public Offices in Jordan

Almasi, A., Mohammadib, M., Azizi, A., Berizi, Z., Shamsi, K., Shahbazi A., Mosavi S.A., 2019. Assessing the knowledge, attitude and practice of the kermanshahi women towards reducing, recycling and reusing of municipal solid waste. Resources, Conservation and Recycling14: 329-338

Alrabie, K., Saidan, M.N., 2018. A preliminary solar-hydrogen system for Jordan: impacts assessment and scenarios analysis. International Journal of Hydrogen Energy 43(19): 9211-9223

Asi, E., Busch, G., Nkengla, L., 2013. The Evolving Role of Women in Sustainable Waste Management in Developing Countries - A Proactive Perspective?. National Conference on Integrated Waste Management and Green Energy Engineering. April 15-16

Bench, M., Woodard, R., Harder, M., Stantzos, N., 2005. Waste minimisation: home digestion trials of biodegradable waste. Resour. Conserv. Recycl. 45: 84-94

Bernad-Beltran, D., Simo, A., Bovea, M.D., 2014. Attitude towards the incorporation of the selective collection of biowaste in a municipal solid waste management system. A case study. Waste Manage. 34: 2434-2444

Bhawal Mukherji, S., Sekiyama, M., Mino, T., Chaturvedi, B., 2016. Resident knowledge and willingness to engage in waste management in Delhi, India. Sustainability 8 (10): 1065

Ezebilo, E.E., 2013. Willingness to pay for improved residential waste management in a developing country. Int. J. Environ. Sci. Technol. 10: 413-422

GTZ, 2005. Private Sector Involvement in Solid Waste ManagementAvoiding Problems and Building on Successes. Deutsche Gesellschaft fürbTechnische Zusammenarbeit (GTZ) GmbHb, Eschborn, Germany

Ibanez Prieto, A., 2018. Women Rights Movement Hails Unprecedented Number of Women in Government. The Jordan Times. http://www. jordantimes.com/news/local/women-rights-movement-hails-unprecedented-number-women-government (accessed on 10 October 2019)

Iyer, E.S., Kashyap, R.K., 2007. Consumer recycling: role of incentives, information, and social class. J. Consum. Behav. 6: 32-47. https:// doi.org/10.1002/cb

Jabr, G., Saidan, M., Al-Hmoud, N., 2019. Phosphorus Recovery by Struvite Formation from Al Samra Municipal Wastewater Treatment Plant in Jordan. Desalination and Water Treatment, doi: 10.5004/ dwt.2019.23608

Khasawneh, H., Saidan, M., Al-Addous, M., 2019. Utilization of hydrogen as clean energy resource in chlor-alkali process. Energy Exploration \& Exploitation 37(3): 1053-1072

Laor, P., Suma, Y., Keawdounglek, V., Hongtong, A., Apidechkul, T., Pasukphun, N., 2018. Knowledge, attitude and practice of municipal solid waste management among highland residents in Northern Thailand. J. Health Res. 32 (2): 123-131

Malkawi, K., 2015. Refugees constitute third of Jordan population World Bank Official. The Jordan Times, Jordan

Mehra, R., Du, T., Nghia, N., Lam, N., Chuyen, T., Tuan, B., Tran, P., Nhan, N., 1996. Women in waste collection and recycling in Ho Chi Minh city. Popul. Environ. 18: 187-199

Ministry of Municipal Affairs (MoMA), 2015. Development of a National Strategy to Improve the Municipal Solid Waste Management Sector in the Hashemite Kingdom of Jordan. Amman, Jordan

Ministry of Water \& Irrigation, MWI, 2015. National Water Strategy 2016-2025, Amman, Jordan

Moh, Y., 2017. Solid waste management transformation and future challenges of source separation and recycling practice in Malaysia. Resour. Conserv. Recycl. 116: 1-14

OXFAM, 2017) TRASH TALK- Turning waste into work in Jordan's Za'atari refugee camp. Oxfam Discussion Papers. Oxfam International August 2017 
Saidan, M.N., Ansour, L.M., Saidan, H., 2017a. Management of Plastic Bags Waste: An Assessment of Scenarios in Jordan. J .Chem. Technol. Metall. 52 (1): 148-154.

Saidan, M.N., Abu Drais, A., Al-Manaseer, E., 2017b. Solid waste composition analysis and recycling evaluation: Zaatari Syrian Refugees Camp, Jordan. Waste Manage. 61:58-66.

Saidan, M.N., Al-Yazjeen, H., Abdalla, A. et al., 2018. Assessment of on-site treatment process of institutional building's wastewater. Processes 6(4):1-13

Saidan, M.N., 2019. Cross-sectional survey of non-hazardous waste composition and quantities in industrial sector and potential recycling in Jordan. Environ. Nanotechnol. Monit. Manage. 12:100227

Saidan, M., Khasawneh, H.J., Aboelnga, H., Meric, S., Kalavrouziotis, I. Hayek, B.O., Al-Momany, S., Al Malla, M., Porro, J.C., 2019. Baseline carbon emission assessment in water utilities in Jordan using ECAM tool. Baseline carbon emission assessment in water utilities in Jordan using ECAM tool. J Water Supply Res T. 68:460-73

Saidan, M.N., Abu Drais, A., Linton, C. et al., 2020. Solid Waste Characterization and Recycling in Syrian Refugees Hosting Communities in Jordan. In: Negm AM and Noama E (eds) Waste Management in MENA Regions, Earth and Environmental Sciences Series, Applied Environmental Science and Engineering for a Sustainable Future, Springer International Publishing AG, part of Springer Nature
Saphores, J., Nixon, H., Ogunseitan, O., Shapiro, A., 2006. Household willingness to recycle electronic waste - an application to California. Environ. Behav. 38:183-208

Schwab, K., Sala-i-Martin, X., 2017. The Global Competitiveness Report 2017 - 2018. World Economic Forum

Roy, N., Schmid, L., 2018. Labour-Intensive Cash for Work Measures and Structured Employment Promotion for Refugees and Vulnerable Groups. GIZ Jordan, $17^{\text {th }}$ May, 2018 UNHCR

Tarawneh, A., Saidan, M., 2013. Households awareness, behaviors, and willingness to participate in E-waste management in Jordan. Int $\mathrm{J}$ Ecosys 3(5): 124-131

The World Bank, 2017. Progress Towards Gender Equality in the Middle East and North Africa Region: A descriptive note on progress and gaps towards gender equality and women's empowerment in the MNA region, produced to provide the situational context to the World Bank Group's Regional Action Plan (RGAP) FY18-23

UNDP, 2015. Socio-economic Inequality in Jordan. Amman, Jordan

UNHCR, 2017. Cash for Work in Za'atari Camp. Basic Needs and Livelihoods Working Group. April 2017. http://reliefweb.int/sites/reliefweb.int/files/resources/April2017CfWfactsheet.pdf 